\title{
Zachowania zdrowotne kobiet z nietrzymaniem moczu
}

\section{Health behaviors of women with urinary incontinence}

BOŻENA WOJTYCKAํㅗㄹ BEATA HAOR ${ }^{2}$

${ }^{1}$ Centrum Diagnostyczno-Lecznicze Barska we Włocławku

${ }^{2}$ Instytut Nauk o Zdrowiu, Państwowa Uczelnia Zawodowa we Włocławku

DOI: http://dx.doi.org/10.21784//wP.2020.009

ISSN:2451-1846

\section{Streszczenie:}

Wstęp. Modyfikacja zachowań zdrowotnych to istotny element profilaktyki oraz leczenia zachowawczego nietrzymania moczu.

Cel. Celem pracy jest analiza zachowań zdrowotnych kobiet z nietrzymaniem moczu.

Materiał i metody. Badanie dotyczyło 100 pacjentek z nietrzymaniem moczu. Wykorzystano metodę sondażu diagnostycznego i metodę szacowania, technikę ankietowania, skali szacunkowej oraz kwestionariusz Inwentarza Zachowań Zdrowotnych.

Wyniki. Kobiety z nietrzymaniem moczu najwyżej oceniły swoje zachowania zdrowotne w kategoriach: zachowań profilaktycznych, prawidłowych nawyków żywieniowych oraz pozytywnego nastawienia psychicznego. Najniżej respondentki oceniły swoje praktyki zdrowotne.

Wnioski. Zachowania zdrowotne kobiet $\mathrm{z}$ nietrzymaniem moczu są interpretowane jako przeciętne.

Słowa kluczowe: nietrzymanie moczu, kobiety, zachowania zdrowotne. 


\begin{abstract}
:
Introduction. Modifying health behaviours is an important element of the prevention and conservative treatment of urinary incontinence.

Aim. The aim of the study is to analyse the health behaviour of women with urinary incontinence.

Material and methods. The study involved 100 patients with urinary incontinence. The diagnostic survey method and the estimation method, the survey technique, the estimation scale technique and the Inventory of Health Behaviour questionnaire were used.

Results. Women with urinary incontinence rated their health behaviours the highest in the following categories: preventive behaviours, correct eating habits and a positive mental attitude. The respondents rated their health practices the lowest.
\end{abstract}

Conclusions. The health behavior of women with urinary incontinence is interpreted as average.

Keywords: urinary incontinence, women, health behaviour.

\title{
Wstęp
}

Nietrzymanie moczu (NTM) według Międzynarodowego Towarzystwa ds. Kontynencji (ang. International Continence Society - ICS) określane jest jako stan, który wiąże się z niekontrolowanym wyciekiem moczu. Należy także pamiętać, że objaw ten wiąże się $\mathrm{z}$ konsekwencjami o charakterze higienicznym, socjalno-społecznym czy zdrowotnym $[1,2,3]$. Jakość życia osób dotkniętych NTM ulega zdecydowanie obniżeniu, szczególnie wtedy, kiedy zostają wręcz zmuszone do rezygnacji z życia zawodowego i aktywności społecznej [4].

Dane epidemiologiczne wskazują, że NTM dotyczy 10\% populacji, 2-krotnie częściej występuje u kobiet niż u mężczyzn [5]. 
Wśród zalecanych metod leczenia zachowawczego NTM podkreśla się znaczenie zmiany stylu życia czyli wzmożenie aktywności fizycznej na rzecz zapobiegania otyłości, modyfikację diety, rezygnację $\mathrm{z}$ używek, unikanie zakażeń układu moczowego [6]. Styl życia jako nawykowy wzorzec postępowania odgrywa istotną rolę $\mathrm{w}$ procesie kształtowania i ochrony zdrowia. Może on przybierać formę zachowań służących utrzymaniu lub przywróceniu zdrowia (zachowania prozdrowotne) oraz zachowań powodujących bezpośrednie lub odległe szkody zdrowotne (zachowania antyzdrowotne) [7,8].

\section{Cel}

Celem pracy jest analiza zachowań zdrowotnych prezentowanych przez kobiety z nietrzymaniem moczu.

\section{Materiał i metody}

Badaniem dotyczącym analizy zachowań zdrowotnych objęto 100 pacjentek Centrum Diagnostyczno-Leczniczego „Barska" we Włocławku, przyjętych do poradni ginekologicznej, pracowni urodynamicznej $\mathrm{w}$ celu wykonania badania lub przyjęcia do oddziału, w związku z planowanym wykonaniem zabiegu operacyjnego. Uczestniczyły w nim kobiety z potwierdzonym nietrzymaniem moczu w wieku 30 - 81 lat. Były to osoby pełnoletnie, poddawane leczeniu, diagnostyce oraz zabiegom chirurgicznym w ramach chirurgii jednego dnia. Respondentki nie miały stwierdzonych zaburzeń poznawczych, wykazywały dobrą sprawność funkcjonalną, umożliwiającą samodzielne wypełnienie kwestionariuszy. 
W aktualnych badaniach wykorzystano metodę sondażu diagnostycznego i szacowania, technikę ankietowania i skali szacunkowej oraz kwestionariusz metryczki i Inwentarz Zachowań Zdrowotnych (IZZ) autorstwa Z. Juczyńskiego, zakupiony w pracowni Testów Psychologicznych Polskiego Towarzystwa Psychologicznego w Warszawie.

Kwestionariusz IZZ może zostać wykorzystywany do prowadzenia badań zarówno wśród osób zdrowych jak i chorych. Zawiera on 24 stwierdzenia, które dotyczą zachowań związanych ze zdrowiem. Poza określeniem ogólnego wskaźnika nasilenia zachowań zdrowotnych, IZZ umożliwia także analizę wyników, które dotyczą ich poszczególnych kategorii takich jak: nawyki żywieniowe, zachowania profilaktyczne, pozytywne nastawienia psychiczne, praktyki zdrowotne. W celu uzyskania ogólnego wskaźnika nasilenia zachowań zdrowotnych zliczono wskazane przez respondentki wartości liczbowe. Wartość wspomnianego wskaźnika mieści się w granicach 24-120 punktów. Wyższa punktacja oznacza większe nasilenie deklarowanych zachowań zdrowotnych. Natomiast ogólny wskaźnik przekształca się na jednostki standaryzowane i interpretuje według skali stenowej. Wyniki w granicach 1-4 stena przyjmuje się określać jako wyniki niskie, w granicach 5-6 stena przeciętne, a 7-10 wysokie. Dodatkowo odrębnie określa się nasilenie czterech kategorii zachowań zdrowotnych w oparciu o średnią liczbę punktów w każdej z nich [9,10,11].

Zebrany materiał na bieżąco wprowadzano do specjalnie opracowanej na potrzeby badań bazy danych programu Excel. Wszystkie obliczenia wykonano za pomocą pakietu 
statystycznego SPSS Statistics 21,0. Uzyskane wyniki badań poddano analizie statystycznej testem $\mathrm{x}^{2}$ dla prób niezależnych. Przyjęto 5\% ryzyka błędu wnioskowania. Wartość prawdopodobieństwa $\mathrm{p}<0,05$ uznano za statystycznie istotną.

\section{Wyniki}

W tabeli 1 zaprezentowano zachowania zdrowotne respondentek $\mathrm{z}$ podziałem na cztery kategorie: prawidłowe nawyki żywieniowe, zachowanie profilaktyczne, pozytywne nastawienie psychiczne oraz praktyki zdrowotne.

Tabela 1. Zachowania zdrowotne badanych

\begin{tabular}{|l|l|l|l|l|l|l|}
\hline $\begin{array}{l}\text { IZZ (Inwentarz } \\
\text { Zachowań } \\
\text { Zdrowotnych) }\end{array}$ & $\mathrm{N}$ & Min & Max & M & SD & $\begin{array}{l}\text { Alfa } \\
\text { Cronbacha }\end{array}$ \\
\hline $\begin{array}{l}\text { Prawidłowe } \\
\text { nawyki } \\
\text { żywieniowe }\end{array}$ & 100 & 11,00 & 29,00 & 19,8600 & 3,69553 & $\mathbf{0 , 8 8}$ \\
\hline $\begin{array}{l}\text { Zachowanie } \\
\text { profilaktyczne }\end{array}$ & 100 & 10,00 & 28,00 & 20,7800 & 4,64188 & $\mathbf{0 , 8 7}$ \\
\hline $\begin{array}{l}\text { Pozytywne } \\
\text { nastawienie } \\
\text { psychiczne }\end{array}$ & 100 & 12,00 & 27,00 & 19,8400 & 3,21210 & $\mathbf{0 , 7 2}$ \\
\hline $\begin{array}{l}\text { Praktyki } \\
\text { zdrowotne }\end{array}$ & 100 & 13,00 & 25,00 & 18,4700 & 3,59982 & $\mathbf{0 , 8 7}$ \\
\hline
\end{tabular}

n- liczba obserwacji; min-wartość minimalna; max-wartość maksymalna; Mwynik średni; SD-odchylenie standardowe

Źródło: wyniki badań własnych. 


\section{Tabela 2. Zachowania zdrowotne badanych $w$ ramach}

poszczególnych kategorii IZZ

\begin{tabular}{|c|c|c|c|c|c|}
\hline $\begin{array}{l}\text { Numer } \\
\text { pozycji }\end{array}$ & $\begin{array}{l}\text { Kategoria: pozytywne } \\
\text { nastawienie psychiczne }\end{array}$ & M & SD & $r$ (it) & $\begin{array}{l}\text { Ładunek } \\
\text { czynnikowy }\end{array}$ \\
\hline 3 & $\begin{array}{lr}\text { Poważnie traktuję } \text { wskazówki } \\
\text { osób } & \text { wyrażających } \\
\text { zaniepokojenie moim zdrowiem }\end{array}$ & 3,62 & 0,97 & 0,858 & 0,276 \\
\hline 7 & $\begin{array}{l}\text { Unikam sytuacji, które wpływają } \\
\text { na mnie przygnębiająco }\end{array}$ & 2,94 & 1,06 & 0,563 & 0,291 \\
\hline 11 & $\begin{array}{l}\text { Staram się unikać zbyt silnych } \\
\text { emocji, stresów, napięć }\end{array}$ & 2,8 & 0,9 & 0,37 & 0,312 \\
\hline 15 & $\begin{array}{l}\text { Mam przyjaciół i uregulowane } \\
\text { życie rodzinne }\end{array}$ & 4,03 & 1,04 & 0,146 & 0,429 \\
\hline 19 & $\begin{array}{l}\text { Unikam takich uczuć, jak gniew, } \\
\text { lęk i depresja }\end{array}$ & 3,04 & 0,96 & 0,894 & 0,308 \\
\hline 23 & Myślę pozytywnie & 3,41 & 0,83 & 0,814 & 0,141 \\
\hline \multicolumn{2}{|c|}{ alfa Cronbacha } & \multicolumn{4}{|l|}{0,87} \\
\hline \multicolumn{2}{|c|}{ \% wyjaśnionej wariancji } & \multicolumn{4}{|c|}{16,44} \\
\hline $\begin{array}{l}\text { Numer } \\
\text { pozycji }\end{array}$ & $\begin{array}{ll}\text { Kategoria: } & \text { zachowanie } \\
\text { profilaktyczne } & \\
\end{array}$ & M & SD & $r$ (it) & $\begin{array}{l}\text { Ładunek } \\
\text { czynnikowy }\end{array}$ \\
\hline 2 & Unikam przeziębień & 3,6 & 0,94 & 0,593 & 0,726 \\
\hline 6 & $\begin{array}{l}\text { Mam zanotowane numery } \\
\text { telefonów służ pogotowia }\end{array}$ & 3,18 & 1,53 & 0,684 & 0,547 \\
\hline 10 & $\begin{array}{l}\text { Przestrzegam zaleceń lekarskich } \\
\text { wynikających z moich badań }\end{array}$ & 3,87 & 0,87 & 0,329 & 0,678 \\
\hline 14 & $\begin{array}{lll}\text { Regularnie zgłaszam się na } \\
\text { badania lekarskie }\end{array}$ & 3,97 & 1,07 & 0,351 & 0,71 \\
\hline 18 & $\begin{array}{l}\text { Staram się dowiedzieć, jak inni } \\
\text { unikają chorób }\end{array}$ & 2,74 & 0,92 & 0,3 & 0,626 \\
\hline 22 & $\begin{array}{l}\text { Staram się } \text { uzyskać } \\
\text { medyczne } \quad \text { i } \quad \text { zrozumieć } \\
\text { przyczyny zdrowia i choroby }\end{array}$ & 3,42 & 0,97 & 0,485 & 0,445 \\
\hline
\end{tabular}




\begin{tabular}{|c|c|c|c|c|c|}
\hline \multicolumn{2}{|c|}{ alfa Cronbacha } & \multicolumn{4}{|l|}{0,79} \\
\hline \multicolumn{2}{|c|}{ \% wyjaśnionej wariancji } & \multicolumn{4}{|l|}{8,79} \\
\hline $\begin{array}{l}\text { Numer } \\
\text { pozycji }\end{array}$ & $\begin{array}{l}\text { Kategoria: prawidłowe nawyki } \\
\text { żywieniowe }\end{array}$ & M & SD & r (it) & $\begin{array}{l}\text { Ładunek } \\
\text { czynnikowy }\end{array}$ \\
\hline 1 & Jem dużo warzyw, owoców & 3,67 & 0,99 & 0,745 & 0,759 \\
\hline 5 & $\begin{array}{l}\text { Ograniczam spożywanie takich } \\
\text { produktów, jak tłuszcze } \\
\text { zwierzęce, cukier }\end{array}$ & 2,94 & 0,93 & 0,855 & 0,354 \\
\hline 9 & Dbam o prawidłowe odżywianie & 3,5354 & 0,81 & 0,765 & 0,46 \\
\hline 13 & $\begin{array}{l}\text { Unikam spożywania żywności z } \\
\text { konserwantami }\end{array}$ & 3,19 & 0,99 & 0,651 & 0,541 \\
\hline 17 & $\begin{array}{l}\text { Unikam soli i silnie solonej } \\
\text { żywności }\end{array}$ & 2,97 & 0,86 & 0,451 & 0,063 \\
\hline 21 & Jem pieczywo pełnoziarniste & 3,59 & 1,16 & 0,09 & 0,491 \\
\hline \multicolumn{2}{|c|}{ alfa Cronbacha } & \multicolumn{4}{|l|}{0,88} \\
\hline \multicolumn{2}{|c|}{ \% wyjaśnionej wariancji } & \multicolumn{4}{|l|}{6,21} \\
\hline \begin{tabular}{|l|} 
Numer \\
pozycji
\end{tabular} & Kategoria: praktyki zdrowotne & M & SD & r (it) & $\begin{array}{l}\text { Ładunek } \\
\text { czynnikowy }\end{array}$ \\
\hline 4 & $\begin{array}{l}\text { Wystarczająco } \\
\text { odpoczywam }\end{array}$ & 2,88 & 0,9 & 0,967 & 0,653 \\
\hline 8 & Unikam przepracowania & 2,67 & 0,85 & 0,715 & 0,662 \\
\hline 12 & Kontroluję swoją wagę ciała & 3,29 & 0,92 & 0,267 & 0,891 \\
\hline 16 & Wystarczająco dużo śpię & 2,69 & 0,81 & 0,478 & 0,328 \\
\hline 20 & Ograniczam palenie tytoniu & 4,01 & 1,41 & 0,653 & 0,365 \\
\hline 24 & $\begin{array}{l}\text { Unikam nadmiernego wysiłku } \\
\text { fizycznego }\end{array}$ & 2,93 & 1,17 & 0,25 & 0,194 \\
\hline \multicolumn{2}{|c|}{ alfa Cronbacha } & \multicolumn{4}{|l|}{0,92} \\
\hline \multicolumn{2}{|c|}{ \% wyjaśnionej wariancji } & \multicolumn{4}{|l|}{6,82} \\
\hline
\end{tabular}

M- średnia arytmetyczna; SD- odchylenie standardowe; r (it)- współczynnik mocy dyskryminacyjnej

Źródło: wyniki badań własnych. 
Najwyższą średnią punktów respondentki uzyskały w ramach kategorii: zachowania profilaktyczne (20,8 pkt.). Z kolei najniższa średnia punktacja dotyczyła praktyk zdrowotnych badanych (18,5 pkt.). Zbliżoną średnią liczbę punktów pacjentki uzyskały w ramach kategorii: prawidłowe nawyki żywieniowe $(19,9$ pkt.) oraz pozytywne nastawienie psychiczne $(19,8$ pkt.).

W tabeli 2 zaprezentowano wyniki uzyskane przez respondentki w ramach kategorii zachowań zdrowotnych.

Najwyższą średnią punktów $\mathrm{w}$ ramach kategorii: pozytywne nastawienie psychiczne respondentki uzyskały w ramach zachowania: Mam przyjaciół i uregulowane życie rodzinne (4,03 pkt.) oraz Poważnie traktuję wskazówki osób wyrażajacych zaniepokojenie moim zdrowiem (3,6 pkt.) Z kolei najniższa średnia punktacja dotyczyła zachowania: Staram się unikać zbyt silnych emocji, stresów, napięć (2,8 pkt.). Zbliżoną średnią punktację pacjentki uzyskały wskazując na pozycję: Myślę pozytywnie (3,4 pkt.), unikam takich uczuć jak lęk, gniew i depresja (3,04 pkt.) oraz Unikam sytuacji, które wpływajq na mnie przygnębiająco (2,9 pkt).

W ramach kategorii zachowanie profilaktyczne najwyższą średnią punktów respondentki uzyskały w pozycji: Regularnie zgłaszam się na badania lekarskie (4,0 pkt) oraz Przestrzegam zaleceń lekarskich wynikających z moich badań (3,87 pkt). Z kolei najniższa średnia punktacja dotyczyła zachowania Staram sie dowiedzieć jak inni unikają chorób (2,74 pkt). Zbliżone średnie punktacje dotyczyły pacjentek $\mathrm{w}$ ramach takich pozycji jak: Unikam przeziębień (3,6 pkt), Staram się uzyskać informacje 
medyczne i zrozumieć przyczyny zdrowia i choroby (3,4 pkt.) oraz Mam zanotowane numery telefonów służb pogotowia (3,2 pkt.).

$\mathrm{W}$ ramach kategorii prawidłowe nawyki żywieniowe najwyższą średnią liczbę punktów respondentki uzyskały w pozycjach: Jem dużo owoców $i$ warzyw (3,7 pkt.) oraz Jem pieczywo pełnoziarniste (3,6 pkt.). Natomiast najniższa średnia punktacja dotyczyła pozycji: Ograniczam spożywanie takich produktów, jak tłuszcze zwierzęce, cukier (2,94 pkt.). Zbliżoną średnią liczbę punktów pacjentki uzyskały $\mathrm{w}$ ramach takich zachowań jak: Dbam o prawidłowe odżywianie (3,54 pkt.), Unikam spożywania żywności z konserwantami (3,19 pkt.) oraz Unikam soli i silnie solonej żywności (2,97 pkt.).

Najwyższą średnią liczbę punktów w kategorii praktyki zdrowotne respondentki otrzymały $w$ ramach pozycji: Ograniczam palenie tytoniu (4,01 pkt.) oraz Kontroluje swoja wage ciała (3,3 pkt.). Z kolei najniższa średnia punktacja dotyczyła pozycji: Unikam przepracowania (2,67 pkt.). Zbliżoną średnią punktację pacjentki uzyskały w ramach takich zachowań jak: Unikam nadmiernego wysiłku fizycznego (2,9 pkt), Wystarczajq̨co dużo odpoczywam (2,9 pkt.) oraz Wystarczająco dużo śpię (2,69 pkt.).

W tabeli 3 zaprezentowano globalną ocenę zachowań zdrowotnych respondentek. 
Tabela 3. Globalna ocena zachowań zdrowotnych badanych

\begin{tabular}{|l|l|l|l|l|l|}
\hline Średnia & $\mathrm{N}$ & $\begin{array}{l}\text { Odchylenie } \\
\text { standardowe }\end{array}$ & Minimum & Maksimum & Wariancja \\
\hline 78,9500 & 100 & 10,94188 & 48,00 & 99,00 & 119,725 \\
\hline
\end{tabular}

Źródło: wyniki badań własnych.

Wyniki badań wskazują, że w globalnej ocenie zachowań zdrowotnych respondentek średnia liczba punktów wyniosła $78,95(S D=10,94)$. Odpowiada to $w$ przeliczeniu na jednostkę standaryzowaną poziomowi 7 stena i jest interpretowane jest jako wynik przeciętny. Analizując poszczególne kategorie zachowań zdrowotnych stwierdzono, że pacjentki najwyżej oceniły swoje zachowania profilaktyczne (średnia liczba punktów: 20,78; $S D=4,64$ ) oraz prawidłowe nawyki żywieniowe (średnia liczba puktów:19,86; $S D=3,69$ ) a także pozytywne nastawienie psychiczne (średnia liczba punktów: 18,84; $\mathrm{SD}=3,59)$. Z kolei najniżej respondentki oceniły swoje praktyki zdrowotne (średnia 18,47; SD=3,59).

W tabeli 4 zaprezentowano poziom zachowań zdrowotnych respondentek.

Tabela 4. Poziom zachowań zdrowotnych badanych

\begin{tabular}{|l|l|l|}
\hline $\begin{array}{l}\text { Poziom zachowań zdrowotnych (jednostka } \\
\text { stenowa) }\end{array}$ & $\mathrm{N}$ & $\%$ \\
\hline NISKI WYNIK (1-4 steny) & 30 & $30 \%$ \\
\hline WYNIK PRZECIĘTNY (5- 6 stenów) & 34 & $34 \%$ \\
\hline WYSOKI WYNIK ( 7-10 stenów) & 36 & $36 \%$ \\
\hline Ogółem & 100 & $100 \%$ \\
\hline
\end{tabular}

Źródło: wyniki badań własnych. 
Największa grupa respondentek prezentuje wysoki poziom zachowań zdrowotnych (36\% - 36 osób). Z kolei przeciętny ich poziom dotyczył 34\% pacjentek (34 osoby) a niski - 30\% badanych (30 osób).

\section{Dyskusja}

Leczenie NTM należy rozpocząć zawsze od zniwelowania czynników ryzyka i położenia nacisku na zmianę stylu życia. Zmiana stylu życia i modyfikacja zachowań obejmują: zapobieganie otyłości i utrzymanie należnej masy ciała, modyfikację diety oraz ilości przyjmowanych płynów (zwłaszcza zawierających kofeinę i napojów gazowanych), unikanie używek (alkohol, nikotyna), regularną, umiarkowaną aktywność fizyczną, unikanie zaparć, leczenie zakażeń układu moczowego [6].

Wśród rekomendacji zawartych w Raporcie Stowarzyszenia Osób z NTM „UroConti” znajdują się zalecenia dotyczące prowadzenia działań edukacyjnych $\mathrm{w}$ zakresie promocji zachowań prozdrowotnych w ramach profilaktyki NTM już od szkoły podstawowej. W Polsce brakuje również profilaktycznych programów NTM adresowanych do osób dorosłych, szczególnie narażonych na ryzyko nietrzymania moczu [6].

Zaawansowanie wieku sprzyja wielochorobowości, której bardzo często towarzyszy nietrzymanie moczu. W badaniach przeprowadzonych przez Muszalik i współautorów wśród osób starszych hospitalizowanych w Klinice i Katedrze Geriatrii w Bydgoszczy, których celem była ocena zachowań zdrowotnych seniorów, wykazano, że prezentowali oni wyższy poziom 
zachowań zdrowotnych w porównaniu ze średnimi dla populacji osób dorosłych. Poziom praktyk zdrowotnych był istotnie wyższy u osób z wyższym wykształceniem oraz niepracujących, $\mathrm{w}$ porównaniu do pozostałych badanych. Z kolei pozytywne nastawienie psychiczne pozostawało $\mathrm{w}$ korelacji ze stanem cywilnym badanych. Natomiast poniżej norm średnich znalazły się prawidłowe praktyki żywieniowe seniorów [12].

W badaniach Kurowskiej i Kudas przeprowadzonych wśród pacjentów w przebiegu niewydolności serca ze średnią wieku 63 lata, wykazano, że badani jako grupa prezentują przeciętny poziom zachowań zdrowotnych. Świadczyć to może zatem o tym, że przestrzegają pewnych zachowań zdrowotnych np. większość z nich nie pali tytoniu. Niemniej jednak pewnych zachowań zdrowotnych nie respektują np. pomiaru masy ciała [13].

Przeciętny poziom zachowań zdrowotnych potwierdzono także w kolejnych badaniach dotyczących pacjentów w przebiegu choroby przewlekłej jaką jest cukrzyca. Kurowska i Figiel wykazały bowiem, że respondenci ze średnią wieku powyżej 60 roku życia prezentowali duże zróżnicowanie zachowań podejmowanych dla utrzymania zdrowia. Nie wykazali optymalnej wiedzy na temat konieczności podejmowania zachowań prozdrowotnych [14].

Zdaniem Hannnestad'a i współautorów NTM u otyłych kobiet występuje 4-5 razy częściej niż w grupie z prawidłową masą ciała [15]. Wartość BMI powyżej 30 jest uważane za czynnik ryzyka popuszczania moczu [16]. Zmniejszenie masy 
ciała często powoduje złagodzenie objawów i poprawia jakość życia chorych $[3,17]$.

Niższą jakość życia kobiet z NTM Bidzan wykazała w zakresie ich sfery rodzinnej (zmiana trybu i stylu życia rodziny, zmniejszenie aktywności seksualnej, obciążenie budżetu domowego), w sferze zawodowej (zmiana planów zawodowych lub nawet rezygnacja $\mathrm{z}$ pracy) oraz sferze społecznej (ograniczenie kontaktów społecznych). Z kolei w badaniu Dutkiewicza i Kapusty wśród kobiet po 50 r.ż. stwierdzono ponadto tendencję do zaburzeń emocjonalnych, wynikających z lęku i wstydu przed zmoczeniem ubrania $[18,19,20]$.

\section{Wnioski}

Zachowania zdrowotne kobiet z nietrzymaniem moczu są interpretowane jako przeciętne.

\section{Zalecenia dla praktyki pielęgniarskiej}

Weryfikacja zachowań zdrowotnych prezentowanych przez kobiety $\mathrm{z}$ nietrzymaniem moczu to niezbędny element planowania i realizacji przez pielęgniarkę działań profilaktycznych, pomocny w ustaleniu niezbędnych modyfikacji i zmian w praktykach zdrowotnych pacjentek.

\section{Bibliografia/Bibliography:}

1. Abrams P, Cardozo L, Fall M, et al. The standardization of terminology of lower urinary tract function: report from the standardization subcommittee of the International Continence Society. Neurourol Urodyn. 2002; 81:1243-1245. 
2. Mouritsen L. Classification and evaluation of prolapse. Clin Obstet Gynecol. 2005;19: 895-911.

3. Barnaś E., Barańska E., Gawlik B., Zych B. Czynniki najbardziej wpływające na jakość życia kobiet $\mathrm{z}$ nietrzymaniem moczu. Hygeia Public Health. 2015; 50(4): 643-648.

4. Blewniewski M. Diagnostyka i leczenie zespołu pęcherza nadreaktywnego - aktualne algorytmy postępowania. Kwartalnik NTM. 2018; 3(66):11 - 12 .

5. Nygaard I, Barber MD, Burgio KL, et al. Prevalence of symptomatic pelvic floor disorders in US women. JAMA. 2008,:300(11): 1311-1316.

6. Pacjent $\mathrm{z}$ NTM $\mathrm{w}$ systemie opieki zdrowotnej 2020. Raport Stowarzyszenia Osób z NTM „UroConti”. Warszawa lipiec 2020. http://www.uroconti.pl/userfiles/file/Raporty/Raport_NTM_2020.pdf [dostęp w Internecie: 30.09.2020]

7. Heszen I., Sęk H. Behawioralne uwarunkowania zdrowia i choroby. W: Heszen I., Sęk H. (red.), Psychologia zdrowia. PWN, Warszawa 2012; 90-104.

8. Gruszczyńska M., Bąk - Sosnowska M., Plinta R. Zachowania zdrowotne jako istotny element aktywności życiowej człowieka. Stosunek Polaków do własnego zdrowia. Hygeia Public Health. 2015; 50(4):558 - 565.

9. Inwentarz Zachowań Zdrowotnych https://www.practest.com.pl/izzinwentarz-zachowan-zdrowotnych [dostęp w Internecie: 30.09.2020].

10. Bojakowska U., Kalinowski P., Kowalska M. E. Ocena wybranych zachowań zdrowotnych przez i po zdiagnozowaniu choroby wśród kobiet $\mathrm{z}$ nowotworem piersi $\mathrm{w}$ oparciu o Inwentarz Zachowań Zdrowotnych Juczyńskiego - badanie wstępne. Journal of Education, Health and Sport. 2016;6(5):29-37. 
11. Juczyński Z. Inwentarz Zachowań Zdrowotnych. [W:] Juczyński Z. (red.) Narzędzia pomiaru w promocji i psychologii zdrowia. Pracownia Testów Psychologicznych Polskiego Towarzystwa Psychologicznego, Warszawa 2012;110-116.

12. Muszalik M., Zielińska - Więczkowska H., Kędziora - Kornatowska K., Kornatowski T. Ocena wybranych zachowań sprzyjających zdrowiu wśród osób starszych w oparciu o Inwentarz Zachowań Zdrowotnych Jurczyńskiego w aspekcie czynników socjo- demograficznych. Probl Hig Epidemiol. 2013;94(3):509-513.

13. Kurowska K., Kudas A. Wpływ zachowań zdrowotnych na jakość życia osób z niewydolnością serca. Folia Cardiologica Excerpta. 2013; 8(1):18.

14. Kurowska K., Figiel O. Poczucie koherencji a zachowania zdrowotne u osób z rozpoznaną cukrzycą typu 2. Nowiny Lek. 2009; 78: 197-205.

15. Hannestad Y.S., Rortveit G., Daltveit A.K., Hunskaar S. Are smoking and other lifestyle factors associated with female urinary incontinence? The Norwegian EPINCONT Study. BJOG. 2003;110(3):247-254.

16. Bart S., Ciangura C., Thibault F. et al. Stress urinary incontinence and obesity. Prog Urol. 2008; 18(8): 493-498.

17. Whitcomb E.L., Horgan S., Donohue M.C., Lukacz E.S. Impact of surgically induced weight loss on pelvic floor disorders. Int Urogynecol J. 2012; 23(8):1111-1116.

18. Bidzan M., Jakość życia pacjentek $\mathrm{z}$ różnym stopniem nasilenia wysiłkowego nietrzymania moczu. Impuls, Kraków 2008:33.

19. Dutkiewicz S., Kapusta K. Nietrzymanie moczu a czynniki ryzyka i jakość życia kobiet w Zakładzie Opiekuńczo- Leczniczym w Kielcach. Prz. Menopauz. 2011;6:493-499. 
20. Klimaszewska K. Społeczny aspekt nietrzymania moczu Pielęgniarstwo XXI wieku. 2017;vol.16, 3(60):57-61. 